\title{
Successful Resolution of Uremic Tumoral Calcinosis with Conven- tional Hemodialysis Using a Low-Calcium Containing Dialysate
}

\section{Saúl Pampa-Saico ${ }^{1,2 *}$, Maite Rivera-Gorrín ${ }^{1,2,3}$, Estefanía Yerovi-León ${ }^{1,2}$, Víctor Burguera ${ }^{1,2}$, Milagros Fernández-Lucas ${ }^{1,2,3}$ and José L Teruel-Briones ${ }^{1,2}$}

${ }^{1}$ Department of Nephrology, Hospital Universitario Ramón y Cajal (HURYC), Spain

${ }^{2}$ Red de Investigación renal (REDinREN), ISCIII, Spain

${ }^{3}$ Department of Medicine, Universidad de Alcala, Spain

*Corresponding author: Saúl Pampa-Saico, Department of Nephrology, Hospital Universitario Ramón y Cajal (HURYC), Madrid, Red de Investigación renal (REDinREN), ISCIII( ERC 10 RD 12/0021/0020), Carretera Colmenar Viejo KM 9.100 CP: 28034, Spain, Email:saups5@hotmail.com

A 40-year-old Caucasian man with End-Stage Renal Disease (ERSD) due unknown cause had been on Continuous Ambulatory Peritoneal Dialysis (CAPD) since 2009 with $3.5 \mathrm{meq} / \mathrm{I}$ calcium dialysate. The patient was anuric with mean values of total weekly Kt/V urea during the last year of $1.87 \pm 0.3$. He was admitted in September 2014 with spontaneous painful on his left buttock which corresponded to a large asymmetry firm mass on physical examination. During the last year he did not receive calcium supplements, vitamin $D$ analogues, corticosteroids and oral anticoagulants (warfarin). He had been prescribed non-calcium-based phosphate binders (sevelamer, 2-4 g/day) which took irregularly.

An axial Computed Tomography (CT) scan (Figure $1 \mathrm{~A})$ and posterior projection of 3D CT scan (Figure 1B) of the pelvic showed a lobular calcified mass on the left hip. The mean values of serum $\mathrm{Ca}, \mathrm{Ca}$ adjusted for albumin, P, Ca $\times$ P product in the last year were $9.1 \pm$ $0.7 \mathrm{mg} / \mathrm{dl}(8.7-10.3 \mathrm{mg} / \mathrm{dl}), 9.4 \pm 0.3(8.7-10.3 \mathrm{mg} / \mathrm{dl})$, $5.9 \pm 0.9 \mathrm{mg} / \mathrm{dl}(2.5-4.5 \mathrm{mg} / \mathrm{dl})$, and $59.1 \pm 6.9 \mathrm{mg}^{2} / \mathrm{dl}^{2}$, respectively. The mean Phosphatase Alkaline (ALP) and iPTH levels were $130 \pm 18 \mathrm{U} / \mathrm{l}(53-128 \mathrm{U} / \mathrm{l})$ and $72.4 \pm$ $22.2 \mathrm{pg} / \mathrm{ml}(12-65 \mathrm{pg} / \mathrm{ml})$ respectively. After diagnosis of Uremic Tumoral Calcinosis (UTC), the patient was managed by intensified doses of PD associated with non-calcium-phosphate binders (lanthanum carbonate, $3 \mathrm{~g} /$ day). After 10 months the patient did not improve and the values of biochemical results was unchanged; probably by poor patient adherence to diet and dialysis prescription. Finally he was transferred to conventional HD (4 hours, 3 days a week) using low-Ca dialysate (2 $\mathrm{meq} / \mathrm{l})$. After six months clinical and radiological regression were observed (Figure 2A) with completely resolution after 12 months (Figure 2B). During this year on HD we observed a mild decreased of mean serum phosphate level $(5.1 \pm 1.5 \mathrm{mg} / \mathrm{dl})$. Did not observe relevant changes in mean Ca adjusted for albumin $(9.5 \pm 0.2 \mathrm{mg} /$ $\mathrm{dl})$, iPTH levels $(99.3 \pm 42.4 \mathrm{pg} / \mathrm{ml})$, and ALP $(118 \pm 16$ $\mathrm{U} / \mathrm{I})$.

UTC is an uncommon but serious complication of dialysis patient characterized by massive subcutaneous soft tissue deposits of calcium-phosphate near the large joints [1]. Although the pathogenesis remains unclear, uncontrolled hyperphosphatemia with a high CaxP product (especially greater than 70 ) and a high secondary Hyperparathyroidism (HPT) are the main factors for its development [2,3]. In our case the UTC appeared after five year in PD without HPT, moderate hyperphosphatemia and probably the positive calcium balance in PD were the main predisposing factor. We decided to transfer him to conventional HD with low-Ca dialysate because he was non-compliance PD patient. After one year UTC totally was resolved despite improvement in phosphate levels was still suboptimal. 


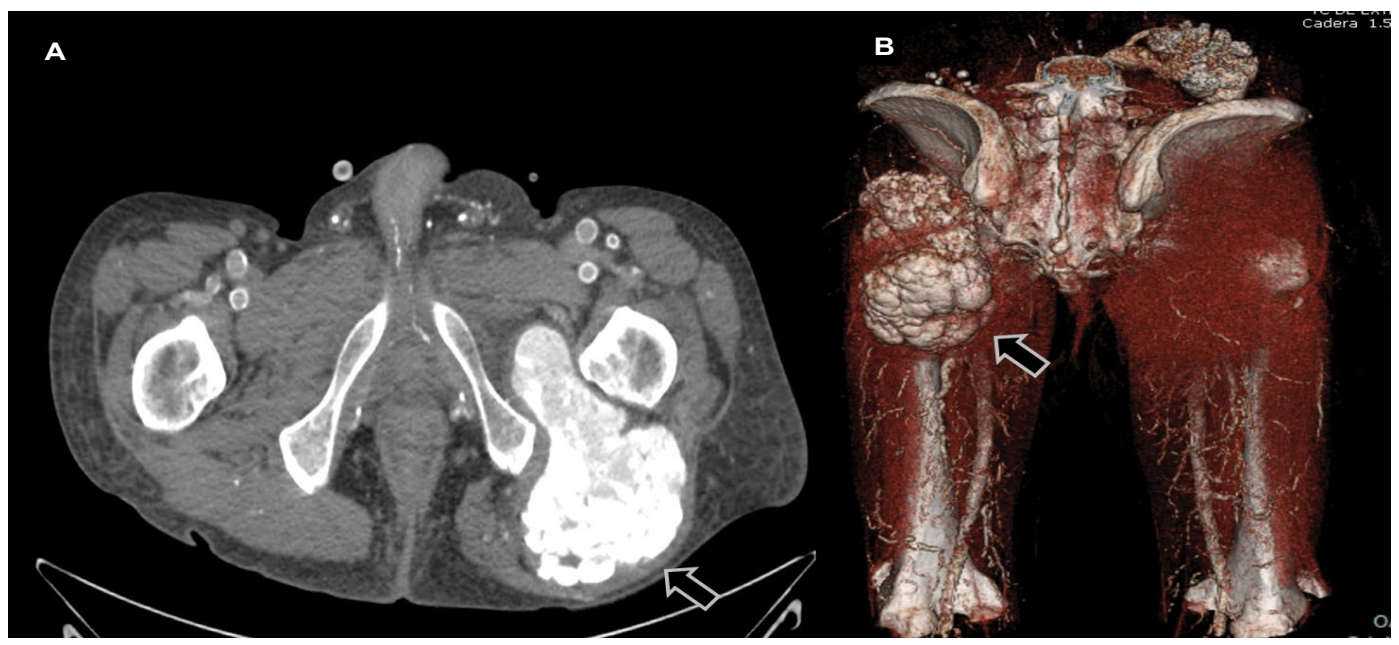

Figure 1: Axial Computed Tomographic (A) scan revealed a lobular extension hyper dense calcification in the gluteus medium with well-defined borders predominantly homogeneous. Posterior 3D CT reconstruction scan of the pelvic showing lobular extense calcification on the left hip joint (B).

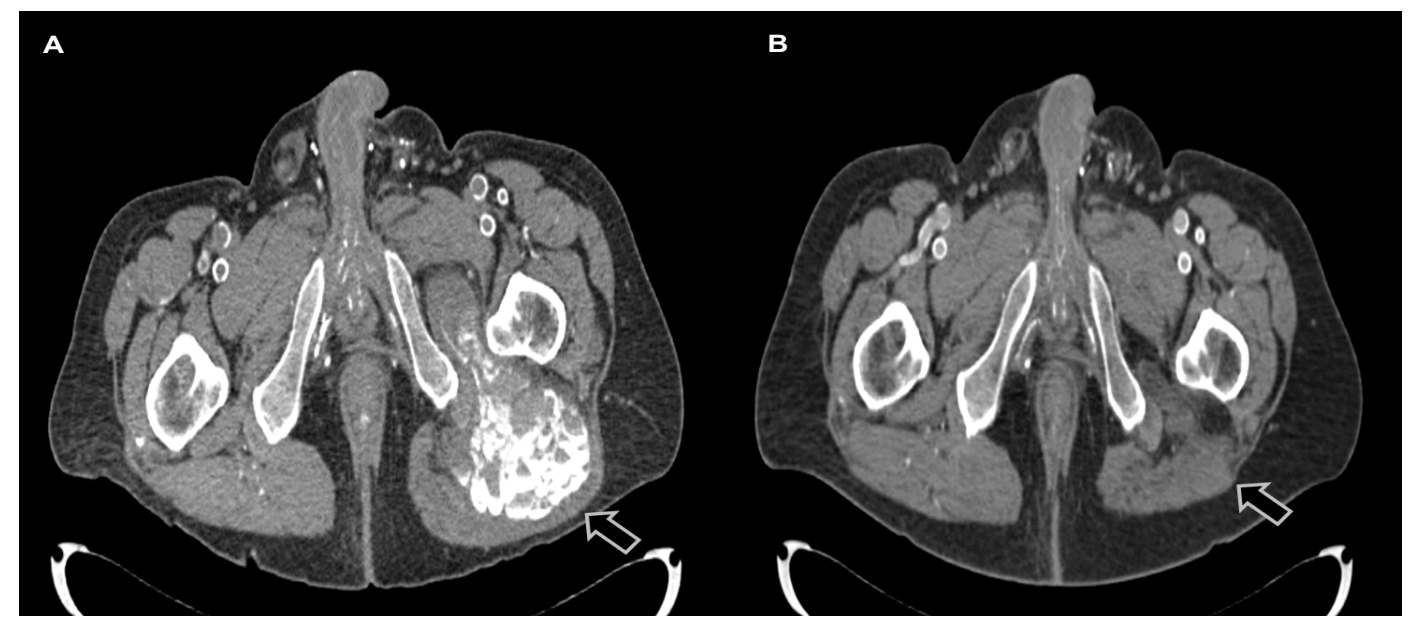

Figure 2: Axial CT scan of the pelvic revealed decrease in deposits of calcium after a six months of conventional HD therapy (A). The calcified mass disappeared after a one year of treatment.

Management of UTC is difficult, surgical excision of the UTC is a treatment option but lesion usually leads to unsatisfactory results because of local recurrence. Kidney transplantation, long-term daily nocturnal HD using low-calcium dialysate have been proposed to effectively decrease and resolve UTC without HPT [4,5]. The complete resolution of UTC of this case treated with conventional HD schedule using low-Ca dialysate suggest that this therapeutic approach continues to be effective alternative therapy for UTC, mainly in non-compliance PD patients.

\section{Conflict of Interest}

No potential conflict of interest relevant to this article was reported.

\section{References}

1. HY Chu, P Chu, YF Lin, HK Chou, SH Lin (2011) Uremic Tumoral Calcinosis in patients on peritoneal Dialysis: clinical, radiologic, and laboratory features. Peritoneal Dialysis International 31: 430-439.

2. Carvalho M, de Menezes IA, Riella MC (2011) Massive painful tumoral calcinosis in a long-term hemodialysis patient. Hemodial International 15: 577-580.

3. Hodnett P, Moore M, Kinsella S, Kelly D, Plant W, et al. (2007) Radiological features of progressive tumoral calcinosis in chronic renal failure. Australas Radiol 51: 115-118.

4. Hamada J, Tamai K, Ono W, Saotome K (2006) Uremic tumoral calcinosis in hemodialysis patients: clinic pathological findings and identification of calcific deposits. J Rheumatol 33: 119-126.

5. Fernandez E, Montoliu J (1994) Successful treatment of massive uremic tumoral calcinosis with daily hemodialysis and very low calcium dialysate. Nephrol Dial Transplant 9: 1207-1209.

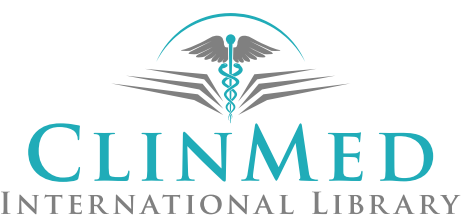

